\title{
Work Values: A Formidable Domain Within the Context of People's Lives
}

\author{
Josephine Pryce
}

James Cook University

\begin{abstract}
Work values occupy a specific domain within the context of people's lives. They govern the importance placed on work and work-related aspects by individuals (and groups of people) within the context of the entirety of their lives. Research on work values indicates that such values are derived from the same basic value systems which guide individuals through the various facets of their lives. As such, they are a specific subset of general life values and are influenced by intrinsic and extrinsic factors. The extant literature contends that various factors, such as demographics, nationality, organisations and occupation have a strong impact on work values. This article utilised an ethnographic approach to examine the ways in which work values can be found in the discursive attitudes and behavioural responses toward work. It explored the literature relating to work values and examined the work values of hospitality workers as a means to understanding differences and dominance in individuals' work values. It found that the work values of frontline hospitality workers are similar in terms of their attitudes to their work as providers of hospitality and stark differences emerged in relation to the work values of managers when contrasted with those of the frontline workers. Work values amongst managerial staff were not congruent. On the one hand, the managerial staff exerted work values commensurate with a higher emphasis on power and authority and a lack of consideration for social values. On the other hand, they exhibited work values indicative of a more altruistic nature. Through these findings, this study contributes to a greater understanding of work values, the meaning of work and the sustainability of working lives.
\end{abstract}

\section{Introduction}

$\mathrm{W}$ ork values occupy a specific domain within the context of people's lives. They govern the importance placed on work and work-related aspects by individuals (and groups of people) within the context of the entirety of their lives. Research on work values indicates that such values are derived from the same basic value systems which guide individuals through the various facets of their lives. In this sense, they are a specific subset of general life values; and so, are influenced by intrinsic and extrinsic factors. The literature contends that factors such as demographics, nationality, organisations and occupation have a strong impact on work values (e.g. Schwartz, 1994). Also, it suggests that there are 'better' and 'not so good' work values, e.g. the idea of the Protestant work ethic. In developing this article, the contention is to examine how the notion of 'work values' is explored in the literature and ascertain how the work values of ordinary individuals illustrates differences and dominance of work values. As part of a bigger research project, this article will add to our understanding of the existence of an hierarchy and domination of work values among individuals and between groups of people; and, whether such understanding can lead to minimisation of dominance of one set of work values over another and so effect greater harmonisation 
specifically in workplaces and amongst workforces. It is argued that such knowledge can assist in ascertaining how to minimise or maximise dominance of one set of work values over another so as to improve working lives and create more sustainable workforces and harmonious workplaces.

\section{The Domain of Work Values}

Understanding values is fundamental to understanding the meaning that individuals place on work (Connor \& Becker, 1975; Furnham, 1987; Rokeach, 1973). This is especially so when attempting to understand the importance the domain of work has in individual's lives. In the area of organisational research, the construct of 'values' has been examined in relation to a range of work-related concepts, including: attitudes (Ajzen \& Fishbein, 1972); job satisfaction (Locke, 1976); employee turnover (Steers \& Mowday, 1981); decision-making (Ravlin \& Meglino, 1987); organisational 'fit' (Rounds, Dawis \& Lofquist, 1987); motivation (Locke, 1991); career choice (Judge \& Bretz, 1992); organizational commitment (Meyer, Irving, \& Allen, 1998); team dynamics (Dose \& Klimoski, 1999); and, organizational citizenship behaviour (Feather \& Rauter, 2004). From such studies, has emerged the notion of 'work values' and the understanding that such values are relevant and important to an individual's work and working life.

In his seminal work, Rokeach (1973, p. 5) defined the term 'value' as an "enduring belief that a specific mode of conduct or end state of existences is personally or socially preferable to an opposite or converse mode of conduct or send state of existence". This definition suggests that values are either terminal (i.e. end state, e.g. creativity) or instrumental (i.e. mode of conduct, e.g. creative). It is indicated that these two different forms of values impact attitudes and behavioiur in different ways. So, it is noted that values are "beliefs and personal standards that guide individuals to function in society" (Chen \& Choi, 2008, p. 596). In addition, Rokeach (1973) contended that values are abstract psychological constructs that inform such constructs as preferences, interests, attitudes, and decision-making. In this sense, they are normative, indicating 'what ought to be' and guide and influence behaviour.

Building on the work of Rokeach, Dose (1997, pp. 227-228) defined work values as, "evaluative standards relating to work or the work environment by which individuals discern what is 'right' or assess the importance of preferences". This definition aligns with the first conceptualisation of 'work values' as proposed by Donald Super in the 1950s who defined the term as "an objective, either a psychological state, a relationship, or material condition, that one seeks to attain" (Super, 1980, p. 130). Zytowski (1970) built on the work of Super and commented that the concept has been aligned with 'work needs' and 'work satisfaction'. Extending the definition, Lyons, Higgins, and Duxbury (2010, p. 971) define work values as:

... generalized beliefs about the relative desirability of various aspects of work (e.g. pay, autonomy, working conditions), and work related outcomes (e.g. accomplishment, fulfilment, prestige) ... [that] represent cognitive expressions of the various needs or goals that are addressed through one's work and working, including monetary security, social interaction, intellectual stimulation, status, esteem and selfactualization needs.

This suggests that work values are aspects of individuals' working lives which are important and relevant to them. It is agreed that work values are a subset of general 'human values' 
(e.g. Roe \& Ester, 1999) and argued that work values are "hierarchically ordered" in individuals' minds according to their importance to the individual (e.g. Lyons et al., 2010). This ordered hierarchy of work values is utilised when individuals make decisions relating to work, jobs and careers (Ravlin \& Meglino, 1987) and applied when individuals make decisions relating to their working lives, such as career development (Super \& Šverko, 1995), work adjustment (Dawis \& Lofquist, 1984) and retirement (reference).

\section{Conceptualising Work Values}

Even so, researchers are varied on their conceptions of the construct of work values. In 1997, Dose (reprinted 2011) presented a review of the literature on work values. In an attempt to provide a more holistic approach to work values, Dose (1997) built on the work of previous researchers and argued that work values can be standards or preferences. She explained that standards enable individuals to distinguish or evaluate whether something is right or wrong, i.e. whether something should or ought to be. Dose (1997) recognised that work values are 'standards' and that they can be characterised by their properties. On the other hand, Dose (1997) contended that preferences are just 'preferences' (either personal or social) and contain no moral element. This rationale led Dose (1997) to define work values as "evaluative standards relating to work or the work environment by which individuals discern what is 'right' or assess the importance of preferences" (pp. 227-228). From this understanding, Dose reasoned that work values could be explained by considering two dimensions: (1) the moral aspect of the value versus individual preference, and (2) the importance or desirability of a value as is determined by the degree of social consensus versus the personal emphasis on these. In line with this argument, Dose proposed a framework for understanding work values where the make-up of work values is governed by these two continuums:

(1) the moral-preference component of the value, and

(2) the personal-social consensus on the importance and desirability of the value

In explaining the framework, Dose (1997) argues that the moral-preference element identifies whether the matter under consideration is 'right', 'wrong' or has no moral aspect. She contends that theories of justice, rights, ethics and utilitarianism are illustrative of standards of right and wrong. Aligned with this, Dose (1997, p. 228) proffers that the moral-preference conceptions are linked with a personal-social consensus dimension, such that along the moral-preference continuum range, certain values are more widely acceptable and "there is a greater social consensus on their desirability". For example, professional codes of practice, protestant work ethic and cross-cultural values tend to have a high degree of moral consideration and of social consensus. Similarly, moral values can be held as individual or social standards, e.g. individual and organisational codes of ethics. In a similar way, Dose (1997) contends that values can be personal and do not always concur with social consensus and equally, the existence of a moral component may be present or not. For example, importance of 'outcomes' relating to work can be intrinsic and so, indicative of personal preferences and have no moral component.

More particularly, Dose (1997) identified four distinct areas of theory and research recognising work values as: an element of vocational and career choice and behaviour (Personal-Preference quadrant); desirable workplace behaviours (Social-Preference quadrant); reflections on the significance and meaning of work (Personal-Moral quadrant); and, the foundation of business ethics (Social-Moral quadrant). The personal-preference quadrant includes ratings of aspects of work which individuals consider to be important, 
leisure 'ethic', aesthetic and affective values, and the meaning of work for individuals, The social-preference quadrant relates to values that are determined by social and cultural factors but have no moral aspect, e.g. success, power, risk and control. The personal-moral quadrant refers to values individuals hold that are not necessarily shared by the broader social community, whether this is society, the culture or the organisation. An example of such values is 'whistleblowing', which may be an individual's moral code but be contrary to the social norms of the organisation. The social-moral quadrant highlights values which accentuate moral duty that is socially shared. Examples of such values include legal codes, organisational codes of ethics and professional codes of practice. Similarly, the Protestant Work Ethic is considered to be determined by social and cultural factors.

In line with Dose's work, contemporary studies examining work values accentuate the strength of individuals' conscious and unconscious frameworks of values and focus on such aspects as: work-related needs (e.g. Macnab \& Fitzsimmons, 1987; Zytowski, 1994); needs satisfactions (Porter, 1961); age (Cherrington, Condie \& England, 1979; Rhodes, 1983); generational (e.g. Smola \& Sutton, 2002; Cennamo \& Gardner, 2008); gender (e.g. Rowe \& Snizek, 1995; Elizur, 1994); cultural factors (e.g. Schwartz, 1999; Ralston, Holt, Terpstra, \& Kai-Cheng, 2008); and, personally-held work values (e.g. Oliver, 1999; Watson,

Papamarcos, Teague, \& Bean, 2004). These individualistic, personal, and demographically oriented factors can lend insights into work values. For example, Dose (1999, p. 102) examined the impact of work values in the formative stages of team life and found that similar or shared work values "may supersede the impact of demographic diversity in producing effective and satisfying relationships".

Additionally, work values are often examined in terms of the importance individuals place on operational facets of work environments and so the concept of work values is associated with concepts such as: job characteristics (Hackman \& Oldham, 1976); work outcomes (Billings \& Cornelius, 1980); vocational needs (Dawis \& Lofquist, 1984); work goals (Harpaz, 1986); and, job choice decisions (Judge \& Bretz, 1992). These approaches lend insights into the importance that individuals place on work-related motivations and incentives, and so, they add to understanding of the concept of work values. Further to these facets, other authors (e.g. Lyons et al., 2010) propose that work values should be considered as 'higher-order' constructs and that themes emerging from assessment of individuals' preferences for various work attributes can provide insights into their underlying work values. In order to capture, this view of work values, Lyons et al. (2010, p. 972) define work values as "the set of underlying desirability criteria that determine one's preferences for these various work aspects". In this way, examination of work-related attributes can extend understanding about individuals work values.

\section{Work Values of Dominance}

As with general values, work values act as criteria individuals utilise in making and enacting work-related choices. Their goals and behaviours are influenced by work values. Previous research shows that work values and general values are distinct but related concepts (Sagie \& Elizur, 1996) with work values are being derived from broader general values (George \& Jones, 1997). Here, it is contended that this is the case and in addition, that the work values are ordered hierarchically. This is not a novel consideration. In fact, it is acknowledged that individuals apply work values when making decisions about their working lives (e.g. career choices) and that the decisions made are in line with the importance individuals place on those work values (Lyons et al., 2010). As an example of research examining dominance of 
work values, van Steden, van der Wal, and Lasthuizen (2013) reported on the values of private security guards ('hybrid' police) comparing them with those of police officers. Interestingly, while there were unique values characteristic to each group, van Steden et al. (2013) found that a 'security ethos' was shared across individuals from either sector. They argued that this security ethos was reflective of the professional culture that was required by both groups.

This notion of shared values in a culture is in line with Schein's (2010) shared basic assumptions, as they relate to culture. Schein (2010, p. 18) defines culture, "as a pattern of shared basic assumptions learned by a group as it solves its problems of external adaptation and internal integration". Schein (2010, p. 28) argues that shared basic assumptions transcend 'dominant value orientations' because the latter "reflect the preferred solutions among several basic alternatives, but all the alternatives are still visible in the culture, and any member of the culture could . . . behave according to the variant as well as dominant orientations". By comparison shared basic assumptions are 'taken-for-granted' to such an extent that there is minimal variation within a social group. Schein (2010) adds that values can over time, transform into assumptions, at both the individual and group levels. The work of Schein (2010) suggests that the hierarchical nature of values proffers dominance of some values over others and that in due course, the dominant values will become assumptions (individuals) or shared assumptions (group/culture). It is beyond the scope of this article to explore this idea of assumptions further, but in order to examine the notion of work values as being hierarchically ordered, it is useful to consider 'types of work values' or differences in work values.

\section{Differences in Work Values}

Exploratory empirical research has yielded several categorisations and typologies of work values (e.g., Lyons et al., 2010; O’Connor \& Kinnane, 1961; Pryor, 1982; Ros, Schwartz, \& Surkiss, 1999). Consistent amongst these researchers is concordance on two fundamental types of work values: (1) intrinsic or cognitive work values; and (2) extrinsic or instrumental work values (e.g. Elizur, 1984; Herzberg, Mausner, \& Snyderman, 1959; Lyons et al., 2010; Ros et al., 1999; Schwartz, 1999). Intrinsic or cognitive work values apply to inherent psychological satisfactions of working, such as interesting, challenging and/or varied work and intellectual stimulation. By contrast, extrinsic or instrumental work values refer to more tangible aspects of work, such as pay, benefits, autonomy, leave and job security. Other types of work values include: social, altruistic or 'humanity', and prestige work values. Social work values refer to relations with co-workers, supervisors and other people (Elizur, 1984; Lyons et al., 2010; Pryor, 1979; Ros et al., 1999; Schwartz, 1999; Super, 1970). Altruistic or 'humanity' work values pertain to the desire to help others and to be involved in work which benefits society (Dawis \& Lofquist, 1984; Finegan, 2000; Lyons et al., 2010; Pryor, 1982; Super, 1970). Prestige work values apply to status, influence, and power (Dawis \& Lofquist, 1984; Lyons et al., 2010; Pryor, 1979; Ros et al., 1999; Schwartz, 1999; Super, 1970). These other work values are often subsumed under intrinsic or psychological work values (Schwartz, 1999).

Various researchers have used facet theory to explore typologies of work values. Facet theory was originally proposed by Louis Guttman in 1954 (Guttman \& Greenbaum, 1998). According to Levy (1994, p. 204), "Facet theory provides new techniques for analysis of multidimensional structures" (Elizur, Borg, Hunt, \& Beck, 1991). It does so by considering a facet as "a conceptional criterion for classifying observational items" and then explaining a 
phenomenon through the systematic classification and structuring of observational items. In their use of facet theory to examine the work values phenomenon, Elizur et al. (1991) contend that the phenomenon of work values consists of two fundamental facets: (1) modality of outcome; and, (2) according to system-performance contingency. The modality of outcome facet consists of three elements: (1) tangible work values (e.g. benefits, security, and pay); (2) cognitive or psychological work values (e.g. learning, abilities, interesting work); and, (3) affective work values which relate to social aspects of work (e.g. co-workers, supervisors). The system-performance contingency facet is based on whether the work is reliant on systemwide aspects (e.g. resources) or is contingent on individuals' performances (e.g. rewards).

Further to the work of Elizur, the research of Ros et al. (1999) and Lyons et al. (2010) indicated the modality facet consisted of four work value types: cognitive (intrinsic), instrumental (extrinsic), social/altruistic, and prestige. These researchers argue that these four work value types are manifestations of higher-order work value types noted in Schwartz's (1992) model of general values, specifically and respectively, openness to change, conservation, self-transcendence, and self-enhancement. Additionally, this parallel between work and general values, supports the idea that work-related values are indicative of general human values (Lyons, et al., 2010; Sagie \& Elizur, 1996).

Recognition of types of work values affords a mechanism for determining the hierarchical ordering of these values, as they relate to the relative importance of those values to individuals and the possibility of value trade-offs when they make decisions about work. Empirical research using types of work values has provided some evidence for hierarchical ordering of work values. For example, Lyons (2003) conducted "An exploration of generational values in life and work". He administered a questionnaire to 1196 Canadian knowledge workers. And found that there were "significant generational differences in nine of the ten general life values examined and in three of the six work values. Lyons (2003) reported that younger generations place more importance on the values associated with openness to change and self-enhancement than do older generations. The older generations, on the other hand, place more importance on altruistic work values. Lyons (2003) states that, there was no evidence in support of the popular belief that the work ethic is in decline amongst younger generations.

Patterson (2011) also explored generational differences in work values but she examined those of "Administrative employees at private institutions of higher education" in North Carolina (US). Patterson (2011) utilised Super's Work Values Inventory-revised, which has 12 work values; and administered it to 131 administrative employees in student services and support positions employed at four higher education institutions. She found that "Generational groups may be more alike than different regarding work values, with the exception of relationships with co-workers and the workplace environment. Generation X ranked 'co-workers' as less important and Matures ranked the 'workplace' as more important. Interestingly, Patterson (2011) also found that females ranked workplace as more important that males.

\section{Job Attributes as Work Values}

In a further study, Combs, Milosevic, Jeung, and Griffith (2012, p. 7) explored the relationship between ethnicity and work values. They rationalised that ethnic identity would impact strongly on individual job attribute preferences. Combs et al. (2012) noted that job 
attribute preferences were work values and defined them as "the degree to which people look for different qualities from their work". For their study, Combs et al. (2012) utilised the job attribute preferences classification of Meyer, et al., (1998): comfort and security, competence and growth, and status and independence. Other studies acknowledged that 'job attributes' can refer to a myriad of aspects related with work, for example they can include: rewards, autonomy, opportunity for advancement, working environment, the opportunity for interaction with others (Beutell \& Brenner, 1986; Konrad, Williams, Linzer, McMurray, Pathman, Gerrity \& Rhodes, 1999; Rowe \& Snizek, 1995). In Combs et al.'s research (2012), comfort and security emphasises regularity, routine, job security and working conditions; competence and growth related to job qualities such as affiliation, opportunity for interaction and social awareness; status and independence referred to opportunities for autonomy in one's work, high income, and preferences for central and prestigious positions that require supervising others rather than interacting with others.

In their research, Combs et al. (2012) contended that job choice is influenced by the interaction of individuals' ethnicity with the process of creativity and continual interaction with others. They found that ethnic identity was more strongly related to competence and growth than to status and independence. This finding suggests that ethnic identity is influential in job preferences. In addition, Combs et al. (2012) noted that collectivism and psychological capital are important mediators in the above relationships and suggested further research in this area. It was noted that collectivism referred to being part of a group; and psychological capital was characterised by the elements of: self-efficacy, optimism, hope, and resilience.

The work of Combs et al. (2012) indicates that a diverse labour market will result in outcomes based on differences in reasons for why people prefer certain jobs or job attributes. This finding is important for several reasons including its usefulness in or improving job satisfaction of employees or increasing representational diversity in workforces. More particularly, it recognises that work values are a key driver in determining the behaviour of individuals in the workplace and that managers need to be more mindful of the presence and pervasiveness of employees' work values. The efficacy of the ubiquitous nature of work values is evident in a study by Uçanok (2008) where 1440 employees responded to an online questionnaire and indicated that differing work values influence the centrality of work in a person's life. Uçanok (2008, p. 167) found that individuals' perceptions of achieving his/her goals through work "affects the importance attached to the act of working" and that the 'predictive power' of work values depends on the centrality work assumes in the life of individuals. Uçanok (2008) concluded that 'work-value congruence' is a key player in explaining individuals' predispositions and behaviours as the dynamics of work values interact, affect and determine beliefs, attitudes and motivations of workers.

\section{The Case of Hospitality Workers}

This article focuses on the notion of work values and uses insights gained from the hospitality industry as a participant observer to examine differences and dominance of work values. In addressing these two key aspects, the article begins with an overview of the concept of work values and a review of past approaches in conceptualising work values. It then discusses the use of typologies and job attributes in examining and understanding work values. Parallel to this discussion, the article offers an experiential interpretation of work values. It utilises a participant observer approach to examine the ways in which work values can be found in the discursive attitudes and behavioural responses toward work by members of three families. 
The article concludes with a discussion of the findings and posits directions for future research.

The hospitality industry is unique in the nature of the work it encapsulates. It is characterised by irregular and long hours, split shifts, labour intensiveness, and is compounded by high casualisation rates, high labour turnover and varying skills levels (Pryce, 2005). In addition, hospitality work is intensive customer-contact, front-line service work that is at times pleasant and rewarding and at others demanding and challenging. Traditionally, the building of a sustainable workforce has been a difficult issue for the hospitality industry (Deery \& Shaw, 1998; Pryce, 2005). Many workers view hospitality work as an intermediary job while they are doing other work, resulting in high labour turnover, absenteeism and short-term commitment. Typically, the industry attracts university students who work in hospitality while undertaking a degree that may be in seemingly unrelated field such as engineering (Pryce, 2005). Equally, it attracts low-skilled workers for whom the hospitality is a good entry point into the workforce. In essence, the reasons why people work in hospitality are varied but the result for the industry is that it struggles to maintain a long-term, committed workforce who view the industry as place to make a career. Invariably, it does attract a unique set of people who are attracted to working with people, providing a service, and tolerate the idiosyncrasies of the job, such as the long hours, the low wages and poor recognition for their status of work. The latter point is in reference to the view that hospitality work is servile work (ibid). In parallel, to these particularities of hospitality work, are the work values of the workers. The building of a workforce that has a strong work ethic, for example, goes a long way in meeting the needs of the industry. Similarly, there is a need for the presence of an organisational culture that values and supports workers with work values that cater to the needs of hospitality work.

This research aimed to explore: (1) difference and dominance of work values in a hospitality environment; and (2) how work values can contribute to positive workplaces. Semistructured, in-depth interviews were conducted with hospitality workers from a hotel in a tropical, regional city as part of a case study exploring the influence of organisational culture on the predispositions of hotel workers. The embedded case presented in this article is part of that broader case study. The research approach was ethnographic and influenced by a social interpretivist paradigm, which allowed the researcher to examine the lives and experiences of hospitality workers through various facets. In doing so, these subjective and varied understandings and meanings of hospitality workers lent insight into the nature of the phenomenon of hospitality work. The social constructivist approach affords a means to explore the reality of peoples' lives (in this case, hospitality workers) as it is constructed and made real through the subject meanings of those individuals (Flick, 2002). The ethnographic approach is recognised for its emic value in allowing the researcher to be immersed in the lives of the people being studied and examine the phenomenon in its natural, social and cultural context (Lewis, 2003).

In this embedded case study, the setting is a restaurant (Apropé, not real restaurant name) in a hotel where a new Food and Beverage (F\&B) Manager had been appointed and immediately sought to 'transform' the F\&B Department into the workplace that he wanted. In a dramatic sweep of change, one of his early decisions was to have "a vibrant, energetic workforce". Quite quickly, it was realised that what the F\&B Manager meant by this was a young workforce. The situation with the restaurant was that the 'breakfast shift' workers were predominantly older women (30 to 50 years old) from various cultural backgrounds who worked in hospitality on a casual basis, generally as a means to supplement their income 
while doing other work, parenting or studying. The 'evening shift' workers were young people, predominantly Australian, who worked in hospitality on a casual basis, in order to earn a living, or because they like hospitality work or they sought to earn some money while studying or back-packing.

As the workforce was casual, it was not unusual for workers not to be given any shifts for periods at a time. However, in the particular restaurant reported here, the workforce had been reasonably consistent with some workers having worked there for over five years on a permanent basis with regular shifts scheduled every week. As an example, the protagonist of this case (called Mary for the purposes of this article) is a mature-age woman who was a food and beverage attendant and had been working for the restaurant for nearly eight years. She came in at five o'clock in the morning, five days a week to work with the chefs in setting-up the buffet ready for the restaurant to open at six-thirty. Mary was reliable, capable of working either independently or as part of a team, and responsible, especially in terms of setting up the buffet to an exceptional standard. When the new F\&B Manager arrived, he cut back Mary's hours to the point where she would sometimes work one shift per week and at other times not work for several weeks. In fact, he had undertaken to cut back the shifts of all the mature-age women who worked the breakfast shift.

For Mary, the work at Apropé was important to her in terms of supplementing her income (she had another part-time permanent job), ability to work early in the morning before going to her "other job" and because of the endearing collegiality she had grown accustomed to over the years while working at Apropé. In addition, for Mary it was a matter of "reciprocity of loyalty", as she said. She had for nearly eight years come in to set-up the buffet and now she was being treated "disrespectfully", as she put it. Mary added, "I work hard, am always her on time, many times much earlier than I am supposed to be here, at no extra cost to the company, and I do it because I care about my work and I want to do a good job and present a good buffet and now I am being treated like rubbish!"

Mary was not the only person upset about the situation but she was most affected in terms of lost shifts and the most vocal in expressing her dissatisfaction with the situation. Most of the others were resigned to the situation and argued that "work is a great part of one's life" but they "wouldn't want to make working in hospitality their life", as one woman said. Less than a month into the new work paradigm, the workers' discontent with their situation became known to the Human Resources Manager, Larry (name changed). Mary had brought the matter to his attention and a meeting was organised between Larry and the 'former' breakfast-shift workers. At the meeting, workers told of their "commitment" and "hard work" and desire to "continue to work in Apropé" and for the hotel. Larry could see that these workers were genuine and he knew that they had "a good work ethic", as he said; and he commented that the former F\&B Manager had often acknowledged to management the "dedication and hard-work of the breakfast crew".

In addition, it had come to Larry's attention that the F\&B Manager was having problems with staff not turning up for their early shifts, in particular the 5:00am shift, and chefs complaining that the buffet was not ready for service; and insisting that disciplinary procedures be enacted immediately. As the matter was investigated, it came to light that the younger workers who were normally reliable and responsible workers struggled to turn up to their early morning shifts for various reasons, some more legitimate and reasonable than others. For example, one girl relied on the bus service, which meant that "the first bus of the day doesn't get to my 
place until 7:30am. So, I can't be here before 8:30am". Equally, others had limited understanding of the requirements for the breakfast set-up and there had been no training.

\section{What Does This Case Show?}

This case suggests that work values are intricately interwoven with job attributes and more specifically, types of work (e.g. service work) or industries (e.g. nursing). As per Coombs et al. (2012), it was evident that the hospitality workers had chosen work which reflected the job attributes and qualities that they desired. For example, an inherent part of Mary's decision to work in hospitality was the money, flexibility of work hours, and the collegiality. Equally, evident from the case is that the centrality of work as a domain in the lives of people varied. For example, Mary seemed to be the most unsettled by the changes in the workplace in comparison to her work colleagues. Uçanok (2008) would argue that this variation in centrality of work is due to differing work values.

The facet approach delineated by Elizur and further developed by Lyons et al. (2010) affords a means for identifying the differences and similarities in work values of the hospitality workers in this case. As noted above, in the model by Lyons et al. (2010), the modality facet consisted of four work value types: cognitive (intrinsic), instrumental (extrinsic), social/altruistic, and prestige. Instrumental values such as benefits, pay and security were a key concern for Mary and prompted her to take a leading voice in going to see the HR Manager. The others were not as concerned about this issue and realised that not getting any shifts was the nature of hospitality work. They seemed to be more philosophical about the situation and the status of work as a domain in their lives. Nonetheless, in their study Chen and Choi (2008) found that comfort and security (about work) were ranked as the most important work value dimensions.

Social facets also impacted on Mary's situation as she valued the collegiality of the workplace. By contrast, the F\&B Manager seemed to be unaware of the social/altruistic facets in the workplace. This is evident in the F\&B Manager's seeming lack of altruism. In their research into hospitality management, Chen and Choi $(2008$, p. 609) talk of "the altruistic aspects of managerial positions" and specifically make reference to the altruistic role of managers in mentoring other employees as a means to enhance relationships, provide a sense of achievement, and promote a more harmonious work environment. This contrasts with the observations of the F\&B Manager in this case, who seemed to be focused on carrying his prestige and exerting his positional authority and power. The workers were respectful of management and this was evident in their relationship with the HR Manager, who exhibited a more altruistic nature. However, they soon realised that the opportunities to develop meaningful relationships with their immediate F\&B Manager were compromised by his outlook and own work values, which were highly instrumental and driven by what Elizur's model would describe as a system-performance contingency facet that is based on the work being reliant on system-wide aspects where the workers are considered to be resources and where activities are weighted by their economic returns. This contrasted with the regime under the previous F\&B Manager, one which the workers were used to. The former manager's work values were oriented more toward a system-performance contingency facet that was contingent upon and valued individuals' performance.

The findings from this case study have shown that within an industry such as the hospitality industry, there can be a congruence of work values. Equally, it has revealed that differences and dominance of work values can impact upon the work environment and the working lives 
of people, in either positive or negative ways. An awareness of the latent and innate nature of work values can go a long way in creating harmonious and positive workplaces and sustainable working lives.

\section{Where To From Here?}

The work of Elizur and Lyons et al. has provided a valuable framework to use in analysing work values and more specifically, in the hospitality industry. However, despite the strides in advancing knowledge and understanding of work values, there still remains much to be ascertained. In 1998, Meglino and Ravlin stated:

We would argue that a basic reason why more progress in understanding value processes in the workplace has not been made is that a reasonably large proportion of the research reported here was not performed with the specific intent of understanding value processes, but with the idea that values or value congruence would explain another phenomenon of interest (for example, see Lee and Mowday's 1987 study of turnover). These studies provide some valuable insights, but tend not to address the function of values per se. This state of the literature is also part of the reason why there continues to be a plethora of definitions, measurement instruments, and specific values used. While in some ways, such diversity is gratifying as values research strives to find a dominant paradigm, it creates some difficulties from the standpoint of making generalizations about the current findings (p. 383).

It would seem that now, nearly fifteen years later, there is still much to be done in understanding 'values', especially as they relate to the meanings individuals place on work and the hierarchical nature of work values. This article showed that to date, various studies have explored work values in light of work-related factors (e.g. gender, age, social aspects, income, and job characteristics). In addition, it has been noted that typologies of work values afford a means of understanding and explaining work values, suggesting that there are differences in work values. Equally, it has also been suggested that work values are hierarchical in nature (Lyons et al., 2010), implying a dominance of some work values over others. The intrinsic and extrinsic nature of work values lends some insights into the degree of importance an individual attributes to particular work values over others. This is further complicated by the fact that work values are a subset of general life values, and that the dominance of intrinsic or extrinsic work values can be affected by broader social or relational values.

Notwithstanding these efforts, definitions and understanding of work values remains broad and largely debated. Furthermore, the majority of studies to date have been quantitative in nature, principally utilising questionnaire surveys. In this study, a qualitative approach was taken to explore the work values of hospitality workers and so, this study adds to our understanding and knowledge of work values from a perspective that has not been utilised previously. Through this approach it was possible to begin to determine the underlying aspects of work values and extricate a more holistic view of the influence of differences and dominance in work values as they play out in the work environment.

\section{Future Research}

From the current study, it is suggested that future research can extend the research using a participant observer or ethnographic approach and interviews with a range of workers from 
various industries, professions and cultures to afford a range of data for determining work values and their hierarchical order, if one does exist. Such future research project could examine the job attributes individuals seek as their preferred choice when looking for a job; and, to see what insights these factors afford in terms of individuals' work values. In addition, it would be worthwhile to determine whether these values are hierarchically construed. Such research could explore associations between workers' gender, age, employment status and educational level with job income and job security and with importance of the work environment and of the job itself. In this way, insights from preferred choice of job attributes when looking for work can provide understanding of the work values of individuals and how these fit in with individuals' general life values.

Additionally, the implications of such work values can be considered in light of individuals' differences in attitudes to work and possible dominance of specific factors which may influence their work values. In this way, the proposed research will be worthy because it explores work values in a manner which has not been attempted previously and it adds to our knowledge and understanding of the concept of work values and more generally, the nature of work and the sustainability of working lives. Such research will be guided by questions such as: How are work values structured? What are the components of work values? What types of work values are there? How are these work values related? How should work values be measured? What are the differences in work values amongst individuals and groups of people? Do work values result in hierarchy and domination? How can an understanding of work values lead us to minimise dominance of one set of work values over another? Addressing such questions will assist in identifying differences in work values and promote understanding of the apparent dominance of one set of work values over another.

\section{Conclusion}

More than ever before, it is incumbent upon employers to be considerate of employees' work values. The modern world requires workplaces which are dynamic, responsive and globally oriented so that they can meet the challenges of the $21^{\text {st }}$ century and into the future. Such workplaces should engage and motivate employees. An understanding of the nature of work values assists employers and employees in creating a workplace where work values act to complement each other rather than create conflict. In so doing, work values can play a central role in fostering positive and healthy workplaces and more broadly, to ameliorate the contested regimes of work.

\section{Works Cited}

Ajzen, I., \& Fishbein, M. (1972). Attitudes and normative beliefs as factors influencing behavioral intentions. Journal of personality and social psychology, 21(1), 1.

Beutell, N. J., \& Brenner, O. (1986). Sex differences in work values. Journal of Vocational Behavior, 28(1), pp. 29-41.

Billings, R. S., \& Cornelius III, E. T. (1980). Dimensions of work outcomes: A multidimensional scaling approach. Personnel Psychology, 33(1), pp. 151-162.

Cennamo, L., \& Gardner, D. (2008). Generational differences in work values, outcomes and 
person-organisation values fit. Journal of Managerial Psychology, 23(8), pp. 891-906.

Cherrington, D. J., Condie, S. J., \& England, L. (1979). Age and Work Values. The Academy of Management Journal, 22(3), pp. 617-623.

Chen, P. \& Choi, Y. (2008). Generational differences in work values: a study of hospitality management. International Journal of Contemporary Hospitality Management, 20(6), pp. $595-615$.

Combs, G. M., Milosevic, I., Jeung, W., \& Griffith, J. (2012). Ethnic Identity and Job Attribute Preferences. Journal of Leadership \& Organizational Studies, 19(1), pp. 516.

Connor, P. E., \& Becker, B. W. (1975). Values and the organization: Suggestions for research. Academy of Management Journal, pp. 550-561.

Dawis, R. V., \& Lofquist, L. H. (1984). A psychological theory of work adjustment: An individual-differences model and its applications. Minnesota, Minneapolis: University of Minnesota Press.

Deery, M. \& Shaw, R. N. (1997), Turnover culture in the hotel industry: An investigation of the concept. Inte4rnational Journal of Hospitality Management, 16(4), 375-392.

Dose, J. J. (1997). Work values: An integrative framework and illustrative application to organizational socialization. Journal of Occupational and Organizational Psychology, 70(3), pp. 219-240.

Dose, J. J., \& Klimoski, R. J. (1999). The diversity of diversity: work values effects on formative team processes. Human Resource Management Review, 9(1), pp. 83-108.

Elizur, D. (1984). Facets of work values: A structural analysis of work outcomes. Journal of Applied Psychology, 69, pp. 379-389.

Elizur, D. (1994). Gender and work values: A comparative analysis. The Journal of Social Psychology, 134(2), pp. 201-212.

Elizur, D., Borg, I., Hunt, R., \& Beck, I. M. (1991). The structure of work values: A cross cultural comparison. Journal of Organizational Behavior, 12(1), pp. 21-38.

Feather, N., \& Rauter, K. A. (2004). Organizational citizenship behaviours in relation to job status, job insecurity, organizational commitment and identification, job satisfaction and work values. Journal of Occupational and Organizational Psychology, 77(1), pp. $81-94$.

Finegan, J. E. (2000). The impact of person and organizational values on organizational commitment. Journal of Occupational and Organizational Psychology, 73(2), pp. 149-169.

Flick U. (2009). An Introduction to Qualitative Research. London: Sage Publications. 
Furnham, A. (1987). Work related beliefs and human values. Personality and Individual Differences, 8(5), pp. 627-637.

George, J. M. \& Jones, G. R. (1997). Experiencing work: Values, attitudes, and moods. Human Relations, 50, pp. 393-416.

Guttman, R. \& Greenbaum, C. W. (1998). Facet theory: Its development and current status. European Psychologist, 3(1), pp. 13-36

Hackman, J. R., \& Oldham, G. R. (1976). Motivation through the design of work: Test of a theory. Organizational behavior and human performance, 16(2), pp. 250-279.

Harpaz, I. (1986). The factorial structure of the meaning of working. Human Relations, 39(7), pp. 595-614.

Herzberg, F., Mausner, B., \& Snyderman, B. B. (1959). The motivation to work: Transaction Pub.

Judge, T. A., \& Bretz, R. D. (1992). Effects of work values on job choice decisions. Journal of Applied Psychology, 77(3), pp. 261.

Konrad, T. R., Williams, E. S., Linzer, M., McMurray, J., Pathman, D. E., Gerrity, M., \& Rhodes, E. (1999). Measuring physician job satisfaction in a changing workplace and a challenging environment. Medical care, pp. 1174-1182.

Lee, T. W., \& Mowday, R. T. (1987). Voluntarily Leaving an Organization: An Empirical Investigation of Steers and Mowday's Model of Turnover. The Academy of Management Journal, 30(4), pp. 721-743.

Lewis I. M. (2003). Social and Cultural Anthropology in Perspective. New Jersey: Transaction Publishers.

Levy, S. (Ed.) (1994). Louis Guttman on Theory and Methodology: Selected Writings. Hamphshire, UK: Dartmouth

Locke, E. A. (1976). The nature and causes of job satisfaction. Handbook of industrial and organizational psychology. Chicago: Rand McNally.

Locke, E. A. (1991). The motivation sequence, the motivation hub, and the motivation core. Organizational behavior and human decision processes.

Lyons, S. T. (2003). An exploration of generational values in life and at work. Ottawa, Ontario: Eric Sprott School of Business.

Lyons, S. T., Higgins, C. A., \& Duxbury, L. E. (2010). Work values: Development of a new three-dimensional structure based on confirmatory smallest space analysis. Journal of Organizational Behaviour, 31, pp. 969-1002.

Macnab, D., \& Fitzsimmons, G. W. (1987). A multitrait-multimethod study of work-related needs, values, and preferences. Journal of Vocational Behavior, 30(1), pp. 1-15. 
Meglino, B. M., \& Ravlin, E. C. (1998). Individual values in organisations: concepts, controversies, and research. Journal of Management, 23(1998), pp. 351-389.

Meyer, J. P., Irving, P. G., \& Allen, N. J. (1998). Examination of the combined effects of work values and early work experiences on organizational commitment. Journal of Organizational Behavior, 19(1), pp. 29-52.

O'Connor, J. P., \& Kinnane, J. F. (1961). A factor analysis of work values. Journal of Counseling Psychology, 8(3), 263.

Oliver, B. L. (1999). Comparing Corporate Managers' Personal Values Over Three Decades, 1967--1995. Journal of Business Ethics, 20(2), pp. 147-161.

Patterson, J. L. F. (2011). Exploring Generational Differences in Work Values of Administrative Employees at Private Institutions of Higher Education. Prescott Valley, Arizona: Northcentral University.

Porter, L. W. (1961). A study of perceived need satisfactions in bottom and middle management jobs. Journal of Applied Psychology; Journal of Applied Psychology, $45(1), 1$.

Pryce, Josephine (2004). The Influence of Organisational Culture on the Service Predispositions of Hospitality Employees. Cairns, Australia: James Cook University.

Pryor, R. (1979). In search of a concept: Work values. Vocational Guidance Quarterly, 27(3), pp. 250-258.

Pryor, R. (1982). Values, preferences, needs, work ethics, and orientations to work: Toward a conceptual and empirical integration. Journal of Vocational Behavior, 20(1), pp. 4052.

Ralston, D. A., Holt, D. H., Terpstra, R. H., \& Kai-Cheng, Y. (2008). The impact of national culture and economic ideology on managerial work values: A study of the United States, Russia, Japan, and China. Journal of International Business Studies, 39(1), pp. 8-26.

Ravlin, E. C., \& Meglino, B. M. (1987). Effect of values on perception and decision making: A study of alternative work values measures. Journal of Applied Psychology, 72(4), 666.

Rhodes, S. R. (1983). Age-related differences in work attitudes and behavior: A review and conceptual analysis. Psychological bulletin, 93(2), pp. 328.

Roe, R. A., \& Ester, P. (1999). Values and work: Empirical findings and theoretical perspective. Applied psychology, 48(1), pp. 1-21.

Rokeach, M. (1973). The nature of human values: Free press.

Rounds, J., Dawis, R., \& Lofquist, L. (1987). Measurement of person-environment fit and prediction of satisfaction in the Theory of Work Adjustment. Journal of Vocational Behavior, 31, pp. 297-318 
Ros, M., Schwartz, S. H., \& Surkiss, S. (1999). Basic individual values, work values, and the meaning of work. Applied psychology, 48(1), pp. 49-71.

Rowe, R., \& Snizek, W. E. (1995). Gender differences in work values. Work and Occupations, 22(2), pp. 215-229.

Sagie, A., \& Elizur, D. (1996). The structure of personal values: A conical representation of multiple life areas. Journal of Organizational Behavior, 17, pp. 573-586.

Schein, E. (2010). Organizational culture and leadership. San Francisco, CA: Jossey-Bass.

Schwartz, S. H. (1992). Universals in the content and structure of values: Theoretical advances and empirical tests in 20 countries. Advances in Experimental Social Psychology, 25, pp. 1-65.

Schwartz, S. H. (1994). Schwartz, S. H. (1994) Are there universal aspect in the structure and content of human values? Journal of Social Issues, 50(4), pp.19-45.

Schwartz, S. H. (1999). A theory of cultural values and some implications for work. Applied psychology, 48(1), pp. 23-47.

Smola, K., \& Sutton, C. D. (2002). Generational differences: Revisiting generational work values for the new millennium. Journal of Organizational Behavior, 23(4), pp. 363-382.

Steers, R. \& Mowday, R. (1981). Employee turnover and post-decision accommodation processes. In B. Staw \& L. Cummings (Eds.), Research in organizational be-havior, Vol. 3, (pp. 235-281). Greenwich, Conn.: JAI Press.

Super, D. E. (1970). Work values inventory: Manual. Riverside Publishing Company.

Super, D. E. (1980). A life-span, life-space approach to career development. Journal of vocational behavior, 16(3), 282-298.

Super, D. E., \& Šverko, B. E. (1995). Life roles, values, and careers: International findings of the Work Importance Study. Jossey-Bass.

Uçanok, B. (2008). The effects of work values, work-value congruence and work centrality on organizational citizenship behaviour. World Academy of Science, Engineering and Technology, 46, pp. 156-169.

van Steden, R., van der Wal, Z., \& Lasthuizen, K. (2013). Overlapping Values, Mutual Prejudices: Empirical Research into the Ethos of Police Officers and Private Security Guards. Administration \& Society, 25, pp. 1-24..

Watson, G. W., Papamarcos, S. D., Teague, B. T., \& Bean, C. (2004). Exploring the dynamics of business values: A self-affirmation perspective. Journal of Business Ethics, 49(4), pp. 337-346.

Zytowski, D. G. (1994). A Super contribution to vocational theory: Work values. The Career Development Quarterly, 43(1), pp. 25-31. 